\title{
The role of parent-adolescent relationships in the development of (pre)hypertension in young adulthood in the US
}

\section{Authors:}

Mak HW, MSc (The corresponding author)

Department of Sociology, University of Cambridge, Free School Lane, Cambridge CB2 3RQ, United Kingdom Email: hwm24@cam.ac.uk; Tel: (0)1223 (3)34520

Kim JE, MSc

Department of Sociology and Criminology, Pennsylvania State University, 513 Oswald Tower, University Park, PA 16802, USA.

Wang S, MA

Department of Sociology, University of Cambridge, Free School Lane, Cambridge CB2 3RQ, United Kingdom

None of the authors has any conflicts of interest, financial or otherwise, to declare; this research is not externally funded, and none of the author has at any time had any dealing with any individual or commercial concern with interests in a related area. 


\begin{abstract}
Background. Hypertension is a strong factor for stroke and coronary disease, and it has been found that 1 in 4 young adults are experiencing pre-hypertension in the US. This study was designed to examine the role of parent-adolescent relationships in the risk of developing (pre)hypertension in young adulthood, and to explore potential mediator(s). Methods. Our analysis was based on the data from the National Longitudinal Study of Adolescent to Adult Health, Wave 1 (ages 13-18) and Wave 4 (ages 25-32) (N=3,350). Three parent-adolescent relationships were extracted from a factor analysis, and four different specifications of (pre)hypertension were generated and tested individually. We applied GSEM to perform path analysis estimations. Results. We found that mother-reported relationship quality had both a direct and an indirect effect via alcohol consumption, on the likelihood of (pre)hypertension in young adulthood. The path from relationship quality to (pre)hypertension via alcohol consumption was consistent with three different specifications of hypertension (prehypertension, clinical/experienced hypertension, and experienced hypertension), suggesting the path relation was evident. Our study also showed that both relationship quality and adolescent-reported maternal warmth/responsiveness were associated with the risk of clinical/experienced hypertension via mental health problems. Parental control was found to have a direct and protective effect on clinical/experienced hypertension. Conclusion. Early family relationships in adolescence predict (pre)hypertension in young adulthood. Initiatives related to parent-adolescent relationships, and the associated effects on later alcohol consumption and mental health problems, may have a long implication on the risk of (pre)hypertension in adulthood.
\end{abstract}

Keywords: Hypertension; Parent-adolescent relationships; Alcohol use; Mental health; Longitudinal dataset; Young adulthood 
2 The study showed protective effects of parent-youth relationship quality, maternal

\section{Implications and Contribution} warmth/responsiveness, and parental control on (pre)hypertension in young adulthood and

4

5

6

7 identified two important mediators: alcohol use and mental health. Interventions may need to be more targeted to family relationships in adolescence and young adult alcohol use and mental health problems.

Hypertension is a strong determinant for stroke and coronary heart disease, the leading causes of death in the United States (US) [1], which costs the nation around \$46 billion each year due to expenditures on health care services and medical treatment for high blood pressure (BP) [2]. While hypertension and its related health problems such as cardiovascular disease (CVD) are more concentrated in the elderly population, the national statistics indicate that nearly 1 in 4 young adults in the US experience pre-hypertension [3,4]. Despite its high prevalence, public and academic awareness over (pre)hypertension among young adults has been relatively low.

There is growing attention on the association between early parent-child/adolescent relationships and later development of hypertension or CVD risk [5,6,7,8,9,10,11,12]. For instance, maternal support during adolescence has been found to correlate with a lower CVD risk in young adulthood, and the association was partly mediated by young adult health behaviours (including tobacco and alcohol use, physical activity, and fast food consumption) [6]. Similarly, having a close relationship with one's mother was related to a lower level of BP and heart rate in adolescence, whereas a hostile parent-child relationship was associated with various CVD risk factors including an accelerated heart rate and an increased BMI [9]. In recognition of parent-adolescent relationships, policymakers and scholars, such as the Triple P 
(positive parenting program) and the World Health Organization, have conducted various family-based interventions to promote positive and responsive parenting $[13,14,15]$.

Although correlations between parent-child/adolescent relationships and hypertensionrelated issues have been demonstrated in previous studies, investigations into the determinants of (pre)hypertension in early adulthood are limited. Considering that a high proportion of young adults are experiencing (pre)hypertension as shown above, and its potential risk of developing into serious hypertension stages that are hard to treat once present, an understanding of its early causes would be useful for designing cost-effective prevention programmes. Therefore, the first objective of this article was to extend previous research by investigating whether (pre)hypertension in early adulthood could be explained by parent-child/adolescent relationships.

Despite the link between early family experiences and hypertension outcome being evident, little is known about the operative mechanisms (i.e. how the early experiences affect later health). An overview of previous literature suggests that early parent-child/adolescent relationships may affect later (pre)hypertension/CVD risks in young adulthood through four health-related behaviours, cigarette use, alcohol consumption, physical activity, and unhealthy diet $[6,16,17,18,19,20,21,22]$, and mental health $[23,24]$. Past literature has demonstrated that poor relationships with parents in childhood and adolescence, especially those that involved low parental warmth, were found to be associated with long-term cigarette and alcohol consumption due to early age at initiation [25]. Chronic exposure to cigarettes and alcohol could change hormone levels that may affect BP, which in turn, would increase the risk of hypertension $[17,19]$. Apart from cigarette and alcohol consumption, research has shown that family cohesion, parental involvement, and parent-adolescent communication were related to increased physical activity and healthy diet; adolescents' self-efficacy in regulating their eating behaviour may partially explain the correlations [9,26]. The activities that emerge in 
adolescence could have a lingering impact on later health behaviours in adulthood, which may increase the risk of (pre)hypertension [27,28]. In terms of mental health problems, warm and responsive parents may provide emotional support for adolescents who are at the sensitive developmental stage in life [23]. Prolonged exposure to mental health problems could induce deregulations in biological systems including continuous secretion of adrenocorticotropic hormone and cortisol, eventually leading to high BP [24]. While previous studies have suggested links between early family relationships, health behaviours, mental health problems and the risk of hypertension/CVD, a substantial connection between them is lacking. As a result, the second objective of this study was to explore the mechanisms underlying this association by testing the indirect effect of parent-adolescent relationships via the four health behaviours and mental health.

To achieve the two objectives, three parent-adolescent relationships were examined in this study: parental warmth and control based on Baumrind's two-factor schema of parenting styles [29], and parent-youth relationship quality, whose unique set of interactions, such as parental trust and joint decision-making, was related to adolescent positive development [30]. Five potential mediators measured in adulthood were tested: cigarette use, alcohol consumption, physical activity, unhealthy diet, and mental health problems. A close examination of the potential long-term impacts of parent-child/adolescent relationships on young adult (pre)hypertension, as well as the possible indirect effects, can provide more specific and targeted policy implications for early life interventions on young adult health.

\section{Data and Methods}

The present research used the public dataset from Wave 1 (aged 13-18) and Wave 4 (aged 25-32) of National Longitudinal Study of Adolescent to Adult Health (Add Health) in 
the US, which provides rich information on multiple aspects of respondents' lives, including family relationships, health status, and health-related behaviours [31].

Add Health is a school-based study of a representative sample of adolescents in grades 7-12 in 1994-1995. Over 90,000 students from 132 schools completed an initial questionnaire, and a sub-sample was selected for in-home interviews in the same year, and were reinterviewed in 1996 (Wave 2), 2001/2 (Wave 3), and 2008 (Wave 4). Parents were also invited for an interview at Wave 1. Of this adolescent-sample, $85 \%$ had a parent participate in the baseline interview. Given that more than $90 \%$ of observations in parent questionnaires were completed by the mother, this study only focused on the relationship with mother.

We restricted the sample to respondents who were between ages 13 and 18 at the time of the first interview, and female respondents who were not pregnant at the time of being diagnosed with high $\mathrm{BP} /$ hypertension, nor pregnant at the time of measuring BP at Wave 4 . The observation was 3,350. To determine whether or not to apply weighting, we followed Solon et al.'s suggestion [32] to conduct the standard heteroscedasticity diagnostics. Since the residuals were normally distributed, weighting was not necessary $[32,33]$. Results presented in this study are therefore unweighted.

Outcome variable. A binary indicator of (pre)hypertension measured at Wave 4 was constructed based on two information: 1) whether respondents had been clinically diagnosed of having high $\mathrm{BP} /$ hypertension, and 2) whether respondents' $\mathrm{BP}$ was higher than normal (BP $\geq$ 120/80 $\mathrm{mm} \mathrm{Hg}$ ) [34] when measured by field interviewers, who administered three readings and recorded participants' BP using a cuff matched to arm circumference. Three alternative binary indicators were also generated for robustness checks: a) pre-hypertension- the measurement in the interview read systolic $120-139$ or diastolic $80-89$; b) clinical/experienced hypertension- respondents who had been either clinically diagnosed with hypertension, or whose $\mathrm{BP}$ measurement was high ( $\mathrm{BP} \geq 140 / 90 \mathrm{~mm} \mathrm{Hg}$ ); and c) experienced hypertension - the 
BP measurement read equal/above 140 systolic or 90 diastolic. The BP classification was constructed based on guidelines from the Seventh Report of the Joint National Committee on Prevention Detection, Evaluation, and Treatment of High Blood Pressure [34].

Early family relationships in adolescence. Early family relationships in adolescence were measured by 18 questions. We applied a principal-component factor analysis to extract three factors: adolescent-reported warmth/responsiveness (Eigenvalue $=4.22, \alpha=0.86,7$ items), mother-reported relationship quality (Eigenvalue $=1.60, \alpha=0.65,4$ items, higher scores indicated higher quality of relationship), and adolescent-reported parental control (Eigenvalue $=2.19, \alpha=0.62,7$ items; parental control was not asked in the parents' questionnaire). Given that parental behaviours might vary according to adolescent age and gender, all scales were therefore adjusted for adolescent age and gender and were standardized $[35]$.

Potential mediators and control variables. Potential mediators examined in this study were measured at Wave 4: respondents' daily cigarette and alcohol consumption in the past 30 days, mental health problems (higher scores indicated greater mental health problems; $\alpha=0.88$, 16 items), weekly physical activities (a 4-point scale, ranging from no exercise to high amount of exercise), and unhealthy diet (an additive scale of having fast food and sweetened drinks in the past week).

Other variables measured at Wave 1 were adjusted: age, gender, ethnicity, high maternal alcohol consumption (two or three days per month or more), and maternal cigarette use. Educational level, employment status, household income, marital status, presence of child(ren), BMI, and religiosity at Wave 4 were also controlled for in all analyses. All measurement responses were provided by the respondents during adolescence and young adulthood, except for parental substance use that was measured only at Wave 1 and reported by either the respondents, mothers, or fathers. 
As the outcome variables were binary, the analyses were based on path analysis estimations using generalised structural equation modelling (GSEM). We specified a system of relationships which allowed parent-adolescent relationships to have a direct effect on the outcome variables, as well as indirect effects via the mediator(s). Control variables were allowed to influence both the mediator(s) and outcomes. Odds ratios are presented.

Our analyses were based on data from human subjects. Because we conducted only secondary analysis of a data set which had been collected under a protocol compliant with federal standards of ethics, informed consent, and the protection of human subjects (see Add Health documentation http://www.cpc.unc.edu/projects/addhealth/faqs/addhealth ) and we had agreed to the relevant conditions of confidentiality and other terms of use, further ethical approval from our own institutions was not required.

\section{Results}

(Table 1)

A full table of descriptive statistics is presented in Table 1. In our data set, around 68\% of the sample was either clinically diagnosed with hypertension or the BP measurement collected during the Wave 4 interview was higher than normal ( $\mathrm{BP} \geq 120 / 80 \mathrm{~mm} \mathrm{Hg}$ ). Nearly half of the sample had pre-hypertension or was at risk of developing hypertension. Around 20$25 \%$ of the respondents experienced hypertension, either they had been clinically diagnosed or the $\mathrm{BP}$ measurement was high $(\mathrm{BP} \geq 140 / 90 \mathrm{~mm} \mathrm{Hg})$. Although the high proportion of hypertension among the young adults in the Add Health study may appear surprising, it has been found that the result was as reliable and valid as another widely cited study, the National Health and Nutrition Examination Survey (NHANES) $[4,36]$. This suggests that the prevalence of hypertension among young adults in the US is unexpectedly high, putting them at a greater risk of CVD disease. 
Table 2 presents estimates from a path analysis using GSEM to estimate the determinants of (pre)hypertension in young adulthood, after adjusting for the control variables. One feature of structural equation modelling is that it provides goodness-of-fit statistics to assess the model fit. However, GSEM estimations using the Stata software are unable to compute goodness-of-fit indices. To address this issue, we performed case-specific residual examinations based on the principle that the residuals should have a mean 0 if the observed and predicted frequencies match well [37]. We found that residuals had a mean very close to 0 ; this suggests that our model was high-quality and fitted well with the data. Moreover, log likelihood, AIC and BIC presented in the table notes indicated that our model was better than the null model.

Our results showed that, of the five mediators, only alcohol consumption was found to be associated with both early family relationships in adolescence and (pre)hypertension in young adulthood. This suggests two important things. First, low-moderate amount of daily alcohol (nearly one drink a day) consumed by the majority of young adults in our study was shown to pose a risk to (pre)hypertension. Second, alcohol consumption served as an important mediator that linked the association between parent-adolescent relationships and the development of (pre)hypertension.

With respect to the three measurements of early family relationships in adolescence, only mother-reported relationship quality had both direct and indirect effects through the mediator on the outcome. Relationship quality was associated with a decrease in the likelihood of having (pre)hypertension ( $\mathrm{OR}=0.908, \mathrm{SD}=0.039, \mathrm{p}<0.05)$. Results also indicated a negative correlation between relationship quality and alcohol consumption $(\mathrm{OR}=0.964, \mathrm{SD}=0.015$, $\mathrm{p}<0.05$ ) and a positive correlation between alcohol consumption and the probability of having (pre)hypertension $(\mathrm{OR}=1.189, \mathrm{SD}=0.067, \mathrm{P}<0.01)$. This suggests that a healthy relationship 
between mother and adolescent, which includes components of parental trust, understanding, and making joint-decisions, may be effective in regulating alcohol use and reducing the risk of (pre)hypertension. Adolescent-reported parental control and maternal warmth/responsiveness were not significantly related to either the mediator or (pre)hypertension in young adulthood. The results were interesting. While it may seem logical to assume that adolescents' perception of parenting styles is more important to their physiological response than parents' perception, what we found here suggest the otherwise: the importance of maternal perception on relationship quality, and a mother's deep interest and active involvement in adolescent's life that was reflected in the variable.

\section{(Table 3)}

Given that only alcohol consumption was shown to be correlated with both quality mother-adolescent relationship and (pre)hypertension, further analysis was conducted. Table 3 reports the estimates of the association between early family relationships in adolescence, alcohol consumption, and alternative indicators of hypertension. Of respondents whose BP measurement indicated pre-hypertension ( $\mathrm{BP} \geq 120-139 / 80-89 \mathrm{~mm} \mathrm{Hg}$ ), neither early family relationships in adolescence nor alcohol consumption predicted the condition. No other mediators were found.

Of respondents who had been diagnosed with hypertension by a clinician or whose BP measurement was high ( $\mathrm{BP} \geq 140 / 90 \mathrm{~mm} \mathrm{Hg}$; clinical/experienced hypertension), again, there was an indirect association between mother-reported relationship quality and clinical/experienced hypertension via alcohol consumption. Interestingly, adolescent-reported parental control indicated a direct and negative relationship with the probability of hypertension $(\mathrm{OR}=0.912, \mathrm{SD}=0.041, \mathrm{p}<0.05$ in both with and without the mediator in the model). This suggests that the effects of parental control may manifest among the respondents with hypertension. No mediator was found to explain the association between parental control 
and hypertension. Further analysis with this specification illustrated that mental health problems were another possible mediator of the association between maternal-reported relationship quality and adolescent-reported maternal warmth/responsiveness and clinical/experienced hypertension. Mental health problems in young adulthood were found to be positively associated with hypertension $(\mathrm{OR}=1.095, \mathrm{SD}=0.050, \mathrm{p}<0.05$; results not shown), and negatively with relationship quality with mother $(\mathrm{OR}=0.959, \mathrm{SD}=0.016, \mathrm{p}<0.05$; results not shown) and maternal warmth/responsiveness $(\mathrm{OR}=0.878, \mathrm{SD}=0.014, \mathrm{p}<0.000$; results not shown). This indicated that, although poor mental health was shown to have no effects when prehypertensive respondents were included in the model, it increased the likelihood of hypertension.

Lastly, for respondents whose $\mathrm{BP}$ was high during the interview $(\mathrm{BP} \geq 140 / 90 \mathrm{~mm} \mathrm{Hg}$; experienced hypertension), and consistent with the original (pre)hypertension variable and clinical/experienced hypertension variable, the amount of alcohol use per day acted as a mediator of the relationship between mother-reported relationship quality and hypertension. No other mediators were found.

For robustness checks, we examined whether adolescent-reported paternal warmth/responsiveness had any effect on the outcome variable and the other specifications. No direct or indirect relationships were found between paternal warmth/responsiveness, the mediators, and any definitions of hypertension.

\section{Discussion}

The field of longitudinal studies connecting the development of physical health in adulthood with early family experiences is growing $[5,6,7,8,9,10,11,12]$. Previous research has demonstrated the association between family relationships and the risk of hypertension/CVD. However, little is known about the effects of parent-adolescent relationships on later 
development of (pre)hypertension in young adulthood and the underlying mechanisms. To fill the research gaps, our study extended the knowledge and made four important contributions.

First, we found that maternal-reported relationship quality with adolescent (e.g. trust and joint decision-making) had a direct and protective effect on the development of (pre)hypertension in young adulthood. The results are in line with previous studies [6,9], and suggest that a close relationship with one's mother may be associated with a lower level of BP, decreased heart rate, a lower CVD risk in young adulthood, and thus a lower hypertension risk in young adulthood. Second, our paper showed no direct effect of adolescent-reported maternal warmth/responsiveness on later (pre)hypertension. Adolescence is a critical period in which the viability of their circumstances (e.g. unstable emotional states) may influence their reports on parental behaviours, as well as the chances of developing (pre)hypertension later in life. Given that the scales of adolescent-reported maternal warmth/responsiveness and maternalreported relationship quality were derived from two different sets of items, we were unable to compare the effects of adolescent perception and maternal perception on parent-youth relationships directly.

Second, by testing multiple mediators, we found that alcohol consumption may be an important mechanism of the association between maternal-reported relationship quality and (pre)hypertension, as well as clinical/experienced hypertension and experienced hypertension in young adulthood. This result is consistent with the existing literature that has implied a connection between early family experience and later health outcomes via alcohol consumption $[16,17]$. Alcohol is the most used substance and light-moderate use is common. However, our study indicated that regular use (one drink per day) may be related to the development of (pre)hypertension, but this can be regulated by having a high-quality relationship with one's parents. Given that the indicator of a high-quality relationship was derived from maternal reports, the results presented here may indicate not only the importance of maternal perception 
of the interactions with their adolescent, but also the deep interest and active involvement of mothers in their adolescent's life that was reflected in their reports.

Third, in line with previous studies $[25,38]$, we found that maternal-reported relationship quality and adolescent-reported maternal warmth/responsiveness could affect the probability of developing clinical/experienced hypertension via mental health problems. This suggests that both indicators could possibly influence the development of (pre)hypertension, but via different routes (i.e. alcohol use and/or mental health problems). Nevertheless, we also speculate that the adolescents' perception of their relationship with parents may be influenced by unobserved characteristics of the adolescents such as personality traits that could also be associated with poor mental health in adulthood. Future studies will be needed to further investigate the relationship between parenting styles, adolescents' personality and psychological well-being, and other health outcomes.

Finally, our study indicated that parental control had a direct and protective effect on clinical/experienced hypertension. The results are consistent with previous studies, which had shown a negative correlation between parental control and monitoring and adverse health outcomes such as adolescent obesity [38,39]. Although, in our study, parental control appeared to be less effective than relationship quality when it came to regulating alcohol (consistent with Van Ryzin et al. study [21]), a possible measurement error in the control scale might exist. Certain aspects of control which were not captured in our scale, for instance monitoring and demandingness, may be more effective in preventing adolescents from drinking. Future work in this area could seek to understand the effects of various parental disciplinary strategies, such as monitoring and demandingness.

There are several potential limitations to this study. First, although we considered a variety of potential confounding factors in the analysis, other unobserved variables such as 
genetic influence and family history of hypertension were not controlled. Second, casual relationships cannot be identified, even though we used a longitudinal dataset and controlled for many variables for the analyses. Nevertheless, the association between parent-adolescent relationships, the mediators, and (pre)hypertension found in this study may give us important information regarding the possible long-term effects of early family experience on the risk of (pre)hypertension in young adulthood.

\section{Summary and Implications}

Our study showed that early family relationships in adolescence predict (pre)hypertension in young adulthood, suggesting that initiatives related to parent-adolescent relationships may have a longer implication on an adolescent's later physical health. We found that relationship quality between mother and adolescent, maternal warmth/responsiveness, and parental control were associated with different types of (pre)hypertension; some of the effects were expressed via alcohol use and mental health problems. Drawing on these results, both parents and young adults who are regular alcohol users should be the main targets of interventions. For instance, for family-based interventions, policymakers can design parenting programs that strengthen family relationships, promote joint decision-making, train parents to be responsive and supportive, and encourage parents to have a positive and open discussion with their children about the consequences of alcohol use. Furthermore, an increase in government funding for local communities could help provide parents and adolescents with more accessible resources and support (emotionally and instrumentally), especially in areas where families are more vulnerable, and where adolescents are at risk of using alcohol regularly and experiencing mental health problems. This could reduce the huge financial burden in society associated family dissolution, specialty care for substance abuse and psychological disorders [40]. Importantly, the government should also increase public awareness of young adult (pre)hypertension and how it can be prevented by early parent-adolescent relationships. 
296 For young adults who are regular drinkers, our paper indicates that daily light-moderate 297 drinking could play a role in their risk of (pre)hypertension. It is important for the US Department of Health and Human Services to revise the low risk alcohol guidelines and further investigate the relationship between light drinking and (pre)hypertension.

Taken together, our paper suggests that different parent-adolescent relationships play various roles in the probability of (pre)hypertension development, either directly or indirectly via alcohol use and mental health problems. To reduce expenditures associated with medical treatment and health care services, establishing healthy family relationships in adolescence could be the earliest and most cost-effective way to prevent young adult (pre)hypertension. 
Table 1. Descriptive statistics for (pre)hypertension, parent-adolescent relationships, potential mediators, and covariates $(\mathrm{N}=3,350)$

\begin{tabular}{|c|c|c|c|c|}
\hline \multirow{2}{*}{\multicolumn{2}{|c|}{ Variables }} & \multicolumn{2}{|c|}{ Range of Values } & \multirow{2}{*}{ Mean (SD) or \% } \\
\hline & & Min & Max & \\
\hline \multicolumn{5}{|l|}{$\begin{array}{l}\text { Outcome variables, W4 } \\
\text { (Pre)hypertension }{ }^{1}\end{array}$} \\
\hline (Pre)hypertension ${ }^{1}$ & & 0 & 1 & 68.2 \\
\hline \multicolumn{5}{|l|}{ Alternative specifications of hypertension } \\
\hline Pre-hypertension² & & 0 & 1 & 47.6 \\
\hline Clinical/experienced hyertension ${ }^{3}$ & & 0 & 1 & 25.4 \\
\hline Experienced hypertension ${ }^{4}$ & & 0 & 1 & 19.0 \\
\hline \multicolumn{5}{|l|}{ Parent-adolescent relationships, W1 } \\
\hline Mother-reported relationship quality & & -4.50 & 2.32 & $-0.00(1.00)$ \\
\hline $\begin{array}{l}\text { Adolescent-reported } \\
\text { warmth/responsiveness }\end{array}$ & maternal & -4.94 & 1.70 & $-0.02(1.01)$ \\
\hline Adolescent-reported parental control & & -1.85 & 4.43 & $-0.01(0.98)$ \\
\hline \multicolumn{5}{|l|}{ Potential mediators, W4 } \\
\hline Daily alcohol use in the past 30 days & & 0 & 6 & $0.96(0.94)$ \\
\hline Daily cigarettes use in the past 30 days & & 0 & 28 & $3.41(6.66)$ \\
\hline Mental health problems & & -1.63 & 4.37 & $-0.03(0.99)$ \\
\hline \multicolumn{5}{|l|}{ Physical activities } \\
\hline No exercise (Ref) & & 0 & 1 & 12.5 \\
\hline Low (1-3 times) & & 0 & 1 & 21.5 \\
\hline Medium (4-7 times) & & 0 & 1 & 26.5 \\
\hline High ( 8 or above 8 times) & & 0 & 1 & 39.5 \\
\hline Unhealthy diet & & 0 & 133 & $18.6(15.8)$ \\
\hline \multicolumn{5}{|l|}{ Covariates, W1 \& W4 } \\
\hline High maternal alcohol use, W1 & & 0 & 1 & 22.5 \\
\hline Maternal smoke, W1 & & 0 & 1 & 48.8 \\
\hline Age, W4 & & 25 & 32 & $28.3(1.67)$ \\
\hline Female, W4 & & 0 & 1 & 54.4 \\
\hline White, W4 & & 0 & 1 & 66.7 \\
\hline \multicolumn{5}{|l|}{ Educational level, W4 } \\
\hline Less than high school (Ref) & & 0 & 1 & 7.04 \\
\hline High school graduate & & 0 & 1 & 15.0 \\
\hline Some post-school training/college & & 0 & 1 & 43.7 \\
\hline Bachelor's degree or higher & & 0 & 1 & 34.2 \\
\hline Employed, W4 & & 0 & 1 & 66.3 \\
\hline \multicolumn{5}{|l|}{ Household income, W4 } \\
\hline Less than $\$ 15,000$ (Ref) & & 0 & 1 & 7.58 \\
\hline$\$ 15,000$ to $\$ 49,999$ & & 0 & 1 & 22.8 \\
\hline$\$ 50,000$ to $\$ 74,999$ & & 0 & 1 & 34.8 \\
\hline$\$ 75,000$ to $\$ 150,000$ or above & & 0 & 1 & 28.4 \\
\hline Missing & & 0 & 1 & 6.42 \\
\hline Married, W4 & & 0 & 1 & 39.9 \\
\hline Presence of child(ren), W4 & & 0 & 1 & 45.9 \\
\hline \multicolumn{5}{|l|}{ BMI, W4 } \\
\hline Underweight less than 18.5 (Ref) & & 0 & 1 & 1.37 \\
\hline Normal: 18.5- 24.9 & & 0 & 1 & 31.5 \\
\hline Overweight: $25-29.9$ & & 0 & 1 & 29.8 \\
\hline Obese I: $30-34.9$ & & 0 & 1 & 18.8 \\
\hline Obese II: 35-39.9 & & 0 & 1 & 9.91 \\
\hline Obese III: 40 or above & & 0 & 1 & 8.69 \\
\hline Religiosity, W4 & & -1.73 & 2.19 & $-0.01(1.01)$ \\
\hline \multicolumn{5}{|c|}{$\begin{array}{l}\text { Note: }{ }^{1} \text { Respondents had been diagnosed by a clinician of having a hypertension or blood pressure (BP) } \\
\geq 120 / 80 \mathrm{~mm} \mathrm{Hg} \text { measured at Wave } 4 \text { interview. }{ }^{2} \mathrm{BP} \geq 120-139 / 80-89 \mathrm{~mm} \mathrm{Hg} \text { measured at Wave } 4 \\
\text { interview. }{ }^{3} \text { Respondents had been diagnosed by a clinician of having a hypertension or } \mathrm{BP} \geq 140 / 90 \\
\mathrm{~mm} \mathrm{Hg} \text { measured at Wave } 4 \text { interview. }{ }^{4} \mathrm{BP} \geq 140 / 90 \mathrm{~mm} \text { Hg measured at Wave } 4 \text { interview. }\end{array}$} \\
\hline
\end{tabular}


Table 2. Path analysis using GSEM estimation: the association between parent-adolescent relationships at Wave 1, potential mediators, and (pre)hypertension in adulthood at Wave $4(N=3,350)$

\begin{tabular}{|c|c|c|}
\hline Variables & $\begin{array}{l}\text { Path to (pre)hypertension, } \\
\text { W4 }\end{array}$ & $\begin{array}{l}\text { Path to alcohol use, } \\
\text { W4 }^{2}\end{array}$ \\
\hline & OR (S.E.) & OR (S.E.) \\
\hline \multicolumn{3}{|c|}{ Parent-adolescent relationships, W1 } \\
\hline Mother-reported relationship quality & $0.908(0.039) *$ & $0.964(0.015) *$ \\
\hline $\begin{array}{l}\text { Adolescent-reported } \\
\text { warmth/responsiveness }\end{array}$ & $1.012(0.042)$ & $0.979(0.015)$ \\
\hline Adolescent-reported parental control & $0.950(0.041)$ & $1.002(0.016)$ \\
\hline \multicolumn{3}{|l|}{ Potential Mediators, W4 } \\
\hline Daily alcohol use in the past 30 days & $1.189(0.067)^{* *}$ & \\
\hline Daily cigarette use in the past 30 days & $1.004(0.008)$ & \\
\hline Mental health problems & $0.934(0.042)$ & \\
\hline \multicolumn{3}{|l|}{ Weekly physical activities ${ }^{1}$} \\
\hline Low (1-3 times) & $0.888(0.136)$ & \\
\hline Medium (4-7 times) & $0.859(0.128)$ & \\
\hline High (8+ times) & $0.849(0.121)$ & \\
\hline \multicolumn{3}{|l|}{ Unhealthy diet } \\
\hline Log Likelihood (null) & -1721.4957 & -6166.8241 \\
\hline Log likelihood & -1713.6562 & -6158.9847 \\
\hline AIC & 3491.312 & 12445.97 \\
\hline BIC & 3687.047 & 12838.78 \\
\hline
\end{tabular}


Table 3. GSEM estimation of the association between parent-adolescent relationships at Wave 1 , alcohol consumption in adulthood, and alternative indicators of hypertension in adulthood at Wave 4

\begin{tabular}{|c|c|c|c|}
\hline & $\begin{array}{l}\text { Pre- } \\
\text { hypertension } 1\end{array}$ & $\begin{array}{l}\text { Clinical/experienced } \\
\text { hypertension }^{2}\end{array}$ & $\begin{array}{l}\text { Experienced } \\
\text { hypertension }^{3}\end{array}$ \\
\hline & OR (S.E.) & OR (S.E.) & OR (S.E.) \\
\hline \multicolumn{4}{|c|}{ Effects of parent-adolescent relationships on Wave 4 outcomes (without mediator) } \\
\hline Mother-reported relationship quality & $0.962(0.035)$ & $1.002(0.044)$ & $0.982(0.047)$ \\
\hline $\begin{array}{l}\text { Adolescent-reported } \\
\text { warmth/responsiveness }\end{array}$ maternal & $0.996(0.036)$ & $1.021(0.045)$ & $1.042(0.051)$ \\
\hline $\begin{array}{l}\text { Adolescent-reported } \\
\text { control }\end{array}$ & $1.020(0.037)$ & $0.912(0.041)^{*}$ & $0.916(0.046)$ \\
\hline Log Likelihood (null) & -2238.5191 & -1696.751 & -1462.0756 \\
\hline Log likelihood & -2236.3233 & -1689.8903 & -1442.4387 \\
\hline AIC & 4536.647 & 3443.781 & 2948.877 \\
\hline $\mathrm{BIC}$ & 4732.324 & 3639.516 & 3144.555 \\
\hline \multicolumn{4}{|c|}{ Effects of parent-adolescent relationships on Wave 4 outcomes (with mediator) } \\
\hline Mother-reported relationship quality & $0.962(0.035)$ & $1.002(0.044)$ & $0.982(0.047)$ \\
\hline $\begin{array}{l}\text { Adolescent-reported } \\
\text { warmth/responsiveness }\end{array}$ maternal & $0.996(0.036)$ & $1.021(0.045)$ & $1.042(0.051)$ \\
\hline $\begin{array}{l}\text { Adolescent-reported } \\
\text { control }\end{array}$ & $1.020(0.037)$ & $0.912(0.041)$ * & $0.916(0.046)$ \\
\hline \multicolumn{4}{|c|}{ Effects of parent-adolescent relationships on alcohol consumption at Wave 4} \\
\hline Mother-reported relationship quality & $0.964(0.015)$ * & $0.964(0.044)^{*}$ & $0.964(0.015)^{*}$ \\
\hline $\begin{array}{l}\text { Adolescent-reported } \\
\text { warmth/responsiveness }\end{array}$ & $0.979(0.015)$ & $-0.021(0.015)$ & $0.979(0.015)$ \\
\hline $\begin{array}{l}\text { Adolescent-reported } \\
\text { control }\end{array}$ & $1.002(0.016)$ & $0.002(0.016)$ & $1.002(0.016)$ \\
\hline \multicolumn{4}{|c|}{ Effects of alcohol consumption on Wave 4 outcomes } \\
\hline Alcohol consumption & $0.962(0.035)$ & $1.136(0.050)^{* *}$ & $1.181(0.055)^{* * *}$ \\
\hline Log likelihood (null) & -6683.8476 & -6142.0795 & -5907.4041 \\
\hline Log likelihood & -6681.6518 & -6135.2188 & -5887.7672 \\
\hline AIC & 13491.3 & 12398.44 & 11903.53 \\
\hline BIC & 13884.12 & 12791.25 & 12296.35 \\
\hline$N$ & 3344 & 3350 & 3344 \\
\hline
\end{tabular}

Note: ${ }^{*}$ sig at $5 \%,{ }^{* *}$ sig at $1 \%,{ }^{* * *}$ sig at $0.1 \%$. All covariates are controlled in the model. ${ }^{1}$ Blood pressure (BP) $\geq 120-139 / 80-89 \mathrm{~mm} \mathrm{Hg}$ measured at Wave 4 interview. ${ }^{2}$ Respondents had been diagnosed by a clinician of having a hypertension or $\mathrm{BP} \geq 140 / 90 \mathrm{~mm} \mathrm{Hg}$ measured at Wave 4 interview. ${ }^{3} \mathrm{BP} \geq 140 / 90 \mathrm{~mm} \mathrm{Hg}$ measured at Wave 4 interview. 


\section{Appendix: Items in measurement scales}

Parenting Styles

Mother-reported relationship quality (all measured on 5-point scales; 1=never, 2=seldom, 3=sometimes, 4=often, 5=always)

How often would it be true for you to make each of the following statement about your child:

You get along well with him/her.

Your child and you make decisions about his/her life together.

You just do not understand him or her [reversed scale].

You feel you can really trust him/her.

Adolescent-reported maternal warmth/responsiveness (all measured on 5-point scales; 1=not at all, 2=very little, 3=somewhat, 4=quite a bit, 5=very much)

How much do you think she [your maternal figure] cares about you?

How close do you feel to your [maternal figure]?

Most of the time, your mother is warm and loving toward you.

Your mother encourages you to be independent.

When you do something wrong that is important, your mother talks about it with you and helps you understand why it is wrong.

You are satisfied with the way your mother and you communicate with each other.

Overall, you are satisfied with your relationship with your mother.

Parental Control (all measured as yes/no)

Do your parents let you make your own decisions about:

The time you must be home on weekend nights

The people you hang around with

What you wear

How much television you watch

What time you go to bed on week nights

Which television programs you watch

What you eat

Potential Mediator: Mental health problems

A measured on a 5 -point scale ( $1=$ never, $2=$ =almost never, $3=$ sometimes, $4=$ fairly often, $5=$ very often) ; measured on a 4-point scale (1=never, 2=rarely, 3=sometimes, 4=often)

A In the last 30 days, how often have you felt that you were unable to control the important things in your life?

A In the last 30 days, how often have you felt confident in your ability to handle your personal problems?

$\wedge$ In the last 30 days, how often have you felt that things were going your way?

$\lambda$ In the last 30 days, how often have you felt that difficulties were piling up so high that you could not overcome them?

How often do you feel isolated from others?

In the past 7 days, you were bothered by things that usually don't bother you.

You could not shake off the blues, even with help from your family and your friends, during the past 7 days.

You felt that you were just as good as other people, during the past 7 days.

You had trouble keeping your mind on what you were doing, during the past 7 days.

You were depressed, during the past 7 days.

You were too tired to do things, during the past 7 days.

You felt happy, during the past 7 days.

You enjoyed life, during the past 7 days.

You felt sad, during the past 7 days.

You felt that people disliked you, during the past 7 days. 
In your day-to-day life, how often do you feel you have been treated with less respect or courtesy than other people?

Source: National Longitudinal Study of Adolescent to Adult Health (Add Health), 1994-2008 [Public Use].

\section{References}

1. Benjamin EJ, Blaha MJ, Chiuve SE, et al. Heart disease and stroke statistics-2017 update: A report from the American Heart Association. Circulation. 2017;135:e1-e458.

2. Mozzafarian D, Benjamin EJ, Go AS, et al. Heart disease and stroke statistics-2015 update: A report from the American Heart Association. Circulation. 2015;e29-322.

3. Zhang Y, Moran AE. Trends in the prevalence, awareness, treatment, and control of hypertension among young adults in the United States, 1999 to 2014. Hypertension. 2017;70(4):736-742.

4. Gooding HC, McGinty S, Richmond TK, Gillman MW, Field AE. Hypertension Awareness and Control Among Young Adults in the National Longitudinal study of Adolescent Health. $J$ Gen Intern Med. 2014;29(8): 1098-1104.

5. Carroll JE, Gruenewald TL, Taylor SE, Janicki-Deverts D, Matthews KA, Seeman TE. Childhood abuse, parental warmth, and adult multisystem biological risk in the coronary artery risk development in young adults study. Proc Natl Acad Sci. 2013;110(42):17149-17153.

6. Doom JR, Gunnar MR, Clark CJ. Maternal relationship during adolescence predicts cardiovascular disease risk in adulthood. Heal Psychol. 2016;35(4):376-386.

7. Evans GW, Kim P, Ting AH, Tesher HB, Shannis D. Cumulative risk, maternal responsiveness, and allostatic load among young adolescents. Dev Psychol. 2007;43(2):341-351.

8. McCarthy-Jones S, McCarthy-Jones R. Body mass index and anxiety/depression as mediators of the effects of child sexual and physical abuse on physical health disorders in women. Child Abus Negl. 2014;38(12):2007-2020.

9. Niu Z, Tanenbaum H, Kiresich E, et al. Impact of childhood parent-child relationships on cardiovascular risks in adolescence. Prev Med. 2018;108:53-59.

10. Repetti RL, Taylor SE, Seeman TE. Risky families: Family social environments and the mental and physical health of offspring. Psychol Bull. 2002;128(2):330-366.

11. Suglia SF, Clark CJ, Boynton-Jarrett R, Kressin NR, Koenen KC. Child maltreatment and hypertension in young adulthood. BMC Public Health. 2014;14:1149.

12. Taylor SE, Lerner JS, Sage RM, Lehman BJ, Seeman TE. Early environment, emotions, responses to stress, and health. J Pers. 2004;72(6):1365-1393.

13. Prinz RJ, Sanders MR, Shapiro CJ, Whitaker DJ, Lutzker JR. Population-based prevention of child 
maltreatment: the US Triple P system population trial. Prev Sci. 2009;10(1): 1-12.

14. Eshel N, Daelmans B, de Mello MC, Martines J. Responsive parenting: interventions and outcomes. Bull World Health Organ.2006;84(12): 991-998.

15. Chu JTW, Farruggia SP, Sanders MR, Ralph A. Towards a public health approach to parenting programmes for parents of adolescents. J Public Health. 2012;34(S1):i41-i47.

16. Maggs JL, Patrick ME, Feinstein L. Childhood and adolescent predictors of alcohol use and problems in adolescence and adulthood in the National Child Development Study. Addiction. 2008; 103(SUPPL 1):7-22.

17. Briasoulis A, Agarwal V, Messerli FH. Alcohol consumption and the risk of hypertension in men and women: A systematic review and meta-analysis. J Clin Hypertens. 2012;14(11):792-798.

18. Diaz KM, Shimbo D. Physical activity and the prevention of hypertension. Curr Hypertens Rep. 2013;15(6):659-668.

19. Halperin RO, Gaziano JM, Sesso HD. Smoking and the risk of incident hypertension in middleaged and older men. Am J Hypertens. 2008;21(2):148-152.

20. Ornelas IJ, Perreira KM, Ayala GX. Parental influences on adolescent physical activity: A longitudinal study. Int J Behav Nutr Phys Act. 2007;4(3):1-10.

21. Van Ryzin MJ, Fosco GM, Dishion TJ. Family and peer predictors of substance use from early adolescence to early adulthood: An 11-year prospective analysis. Addict Behav. 2012;37(12):13141324.

22. Winkelmayer WC, Stempfer MJ, Willett WC, Curhan GC. Habitual caffeine intake and the risk of hypertension in women. JAMA. 2005;294(18):2330-2335.

23. Ozer EJ, Flores E, Tschann JM. Parenting style, depressive symptoms, and substance use in Mexican American adolescents. Youth Soc. 2011;45(3):365-388.

24. Meng L, Chen D, Yang Y, Zheng Y, Hui R. Depression increases the risk of hypertension incidence: A meta-analysis of prospective cohort studies. J Hypertens. 2012;30(5):842-851.

25. DeWit DJ, Adlaf EM, Offord DR, Ogborne AC. Age at first alcohol use: A risk factor for the development of alcohol disorders. Am J Psychiatry. 2000;157(5):745-750.

26. Ornelas IJ, Perreira KM, Ayala GX. Parental influences on adolescent physical activity: A longitudinal study. Int J Behav Nutr Phys Act. 2007;4(3):1-10.

27. Dhingra R, Sullivan L, Jacques PF, Wang TJ, Fox CS, Meigs JB, D'Agostino RB, Gaziano JM, Vasan RS. Soft drink consumption and risk of developing cardiometabolic risk factors and the metabolic syndrome in middle-aged adults in the community. Circulation. 2007;116(5):480-488.

28. Huai P, Xun H, Reilly KH, Wang Y, Ma W, Xi B. Physical activity and risk of hypertension: A meta-analysis of prospective cohort studies. Hypertension. 2013;62(6):1021-1026.

29. Baumrind $\mathrm{D}$. The influence of parenting style on adolescent competence and substance use. J Early Adolesc. 1991;11(1):56-95.

30. Mogro-Wilson C. Parental factors associated with Mexican American adolescent alcohol use. J 
Addict. 2013:1-9.

31. Harris KM, Halpern CT, Whitsel E, et al. The National Longitudinal Study of Adolescent to Adult $\begin{array}{llll}\text { Health: Research Design } & 2009 .\end{array}$ http://www.cpc.unc.edu/projects/addhealth/design. (accessed on March 1, 2018).

32. Solon G, Haider SJ, Wooldridge J. What are we weighting for? J Hum Resour. 2015;50(2):301316.

33. Winship C, Radbill L. Sampling weights and regression analysis. Sociol Methods Res. 1994;23(2):230-257.

34. Entzel P, Whitsel EA, Richardson A, Tabor J, Hallquist S, Hussey J, Halpern CT, Harris KM. Add Health Wave IV documentation: Cardiovascular and anthropometric measures. 2009. http://www.cpc.unc.edu/projects/addhealth/documentation/guides/Wave_IV_cardiovascular_and _anthropometric_documentation_111909_revised.pdf (accessed on March 1, 2018).

35. Belsky J. The determinants of parenting: A process model. Child Dev. 1984;55(1):83-96.

36. Nguyen QC, Tabor JW, Entzel PP, et al. Discordance in national estimates of hypertension among young adults. Epidemiology. 2011;22(4):532-541.

37. Lombardi S, Santini G, Marchetti GM, Focardi S. Generalised structural equations improve sexualselection analyses. PLoS ONE. 2017;12(8): e0181305.

38. Aquilino W, Supple A. Long-term effects of parenting practices during adolescence on well-being outcomes in young adulthood. Journal of Family Issues, 2001;22(3):289-308.

39. Stang J, Loth KA. Parenting style and child feeding practices: potential mitigating factors in the etiology of childhood obesity. J Am Diet Assoc. 2011;111(9):1301-13-5.

40. U.S. Department of Health and Human Services (HHS) \& Office of the Surgeon General U.S. (2016). Facing Addiction in America: The Surgeon General's Report on Alcohol, Drugs, and Health. In: U.S. Department of Health and Human Services (HHS), ed: Washington, DC: HHS; 2016. https://addiction.surgeongeneral.gov/sites/default/files/surgeon-generals-report.pdf (access on July 28, 2018) 